\title{
Direct Influence Of English Teachers In The Teaching Learning Process
}

Hafiz Muhammad Inamullah, Institute of Education and Research, Kohat University, Pakistan Ishtiaq Hussain, Institute of Education and Research, Kohat University, Pakistan M .Naseer ud din, Institute of Education and Research, Kohat University, Pakistan

\begin{abstract}
Teachers play a vital role in the classroom environment. Interaction between teacher and students is an essential part of the teaching/learning process. An educator, Flanders originally developed an instrument called Flanders Interaction Analysis (FIA). The FIA system was designed to categorize the types, quantity of verbal interaction and direct and indirect influences of the teachers in the classroom; finally, the information is plotted on a matrix to be analyzed and interpreted. This system consists of ten categories, namely, accepting feelings, praising or encouraging, using student ideas, asking questions, lecturing, giving directions, criticizing or justifying student responses, student-initiated discussion, and silence/confusion. FIA became a widely used coding system to analyze and improve teacher-student interaction patterns. Few studies have been carried out regarding classroom interaction in Pakistan on this vital aspect of the teaching-learning process. The objectives of the study are to explore the direct influence of the teachers in the college level teaching-learning process in the subject of English: to know about positive and negative reinforcement in the class and to analyze the student participation level in the classes at the North West Frontier Province of Pakistan (using the FIA system). This study was significant because its findings and conclusions may stimulate English teachers to improve their teaching behaviour in order to maximize student learning. Fifty college level classrooms were randomly selected as a sample of this study. Fifty observations were carried out, each in one classroom, using Flanders Interaction Analysis system to secure the data. To do this, time sampling was used and each classroom was observed for 810 seconds (13.50 minutes) of a 45minutes class. After obtaining and encoding the data, it was tabulated, analyzed and interpreted by using simple method. 1. The ratio between indirect influence and direct influence: The sum of column 1, 2, 3, 4, divided by the sum of columns 5, 6, 7 gives the ratio. 2. The ratio between positive reinforcement and negative reinforcement: The sum of column 1, 2, 3 is to be divided be the sum of 6, 7. 3. Student participation ratio: The sum of column 8, 9 is to be divided by total sum. The results showed the direct influence of the teacher at college level in the subject of English. The study revealed that the student's participation level was very low in the teachinglearning process. The majority of the teachers were direct in their behavior. The ratio showed that the teachers were more direct in their teaching.
\end{abstract}

\section{INTRODUCTION}

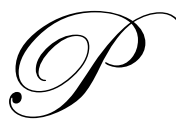

akistan has paid dearly for neglecting education. Our position in the comity of nations has gone down. Pakistan, after 50 years of its existence, does not find itself in an enviable position. Out of 175 countries in the world, its ranking order in terms of human development profile is 139 (UNDP, 1997).

The education system in Pakistan depicts an undesirable situation, especially the classroom environment. The education process in the country (at all levels) is too weak and the classroom environment is totally based on rote memorization. 
Research on teaching effectiveness based on large-scale meta-analysis conducted by Walberg (1986) indicates that there are seven key factors of effective teaching: engaged academic learning time, use of positive reinforcement, cooperative learning activities, positive class atmosphere, higher-order questioning, cues and feedback and use of advanced organizers. The system of interaction developed by Flanders shows how these elements fit together in actual classroom interaction.

\section{Teaching Models}

Teaching elements can also be grouped into three general models of teaching. In the first model, the emphasis is on the transmission of knowledge. Use of advanced organization and direct teaching methods are its main features. The second model involves inquiry- or discovery-based teaching. It emphasizes the indirect method of open-ended questioning and building on student ideas. The focus of the third model is the quality of interpersonal relations. A positive classroom atmosphere is a central component of this model. Joyce emphasizes the need for a variety of teaching models. Instead of relying exclusively on any single model, he suggests synthesizing these models. Teachers therefore need to practice the different skills involved (Norman and Richard, 1994).

The role of the teacher in making the classroom climate conducive to improved learning is highly crucial. The classroom climate is built up by the pattern of interaction between the teacher and student verbal exchanges, asking questions, responding and reacting. The most important factor in a classroom situation is the interactions and exchanges initiated by the teacher and students.

English is taught as a compulsory subject from elementary school through college. Pakistan's education process at the college level is too weak-especially in English. There is no provision for the development of intellectual and thinking skills among students who are given little time for active participation and interaction. The teacher seems to be in a very dominant role in the English class. Unfortunately, the poorly structured classroom quickly deteriorates into a vacuous waste of time.

Flanders has categorized the interactions of teachers and pupils in the classrooms. There are ten categories in the system: of the ten categories in the system, seven are assigned to the teacher's vocalizations, two to the student's vocalizations, and the tenth category classifies pauses, short periods of silence and communication that is confusing or noisy. The seven categories assigned to teacher are again divided into indirect and direct influence. Categories 1 to 4 represent indirect influence and categories 5 to 7 represent direct influence. Indirect influence encourages student participation and freedom of action. Direct influence increases the active control of the teacher and often aims at conformity and compliance. Direct influence tends to increase the teacher's activity and restrains student behavior. The net effect is less freedom of action for the students.

The division of student vocalizations into categories 8 and 9 provides a clue to the nature of freedom given to the students. Usually, but not necessarily, an excessive or above average pattern of direct teacher influence is associated with less student talk. An above average indirect pattern is associated with more student talk (selfinitiated). The use of only two categories to indicate all types of student vocalizations neglects a great deal of information but the major purpose of this system is the analysis of teacher influence. The purpose of category 10 is to record pauses, silence and periods of confusion. This is not intended to record longer periods of silence or confusion that exists for more than two minutes.

Some people feel that Flanders work has underscored the fact that a teacher's verbal domination of the classroom conditions students to become passive and to be dependent on the teacher. This dependency has adverse effects on student attitudes toward learning and his or her performance in school. Flanders found that when teachers are trained in his observation technique and become aware of the importance of language in the classroom, their verbal monopoly decreases. To use the Flanders Interaction Analysis, one codes the verbal interaction in one of the ten categories in the Flanders Interaction Analysis Coding Instrument (Gay, 2000).

Few researches have been carried out in Pakistan on the influence of teachers in the classrooms. There is a need to study the influence of the teachers in the classrooms in the light of Flanders interaction analysis system. 
The present study was designed to investigate the direct influence of the teachers in the college level classrooms, teaching English, in the light of Flanders interaction analysis system, in the North West Frontier Province of Pakistan. The study was further delimited to District Kohat, Peshawar, Abbot Abad, Swat and D.I.khan. The major objectives of the study were to:

1. explore the direct influence of the teachers at college in English

2. learn about positive and negative reinforcement in the class

3. analyze student participation level(s) in the college level classes.

\title{
POPULATION
}

As the purpose of the study was to explore the direct influence of college English teachers in the light of Flander's Interaction analysis, the target population comprised all the English teachers and students in the North West Frontier Province of Pakistan.

\section{SAMPLE}

The sample of the study consisted of fifty college classrooms. The numbers of observed English teachers were fifty. The total number of observed English students was 2,700. All the fifty classes were selected randomly from each District. The study was further delimited to two colleges each of District Kohat, Peshawar, Abbot Abad, Swat and D.I.khan.

The names of selected institutions for the purpose of study are given below.

\author{
S.No Name of Colleges. \\ 1 Government College Peshawar. \\ 2 Islamia College Peshawar \\ 3 Government College swat. \\ 4 Govt girls degree College Abbot Abad \\ 5 Government College Abbot Abad \\ 6 Frontier Education Foundation Girls Degree College Kohat. \\ 7 Govt Girls Degree College D.I Khan \\ 8 Govt Girls College Swat \\ 9 Govt Degree College Kohat \\ 10 Govt Degree College \# 1 D.I Khan
}

\section{RESEARCH INSTRUMENT}

The instrument was developed by Flander (1970) and has been used extensively in various studies. The items in the Flanders Interaction Analysis were converted in an observation sheet as illustrated by Gay (2000).

The Flanders Interaction Analysis system and specimen of observational sheet is given below. 


\section{Flander's Interaction Analysis System}

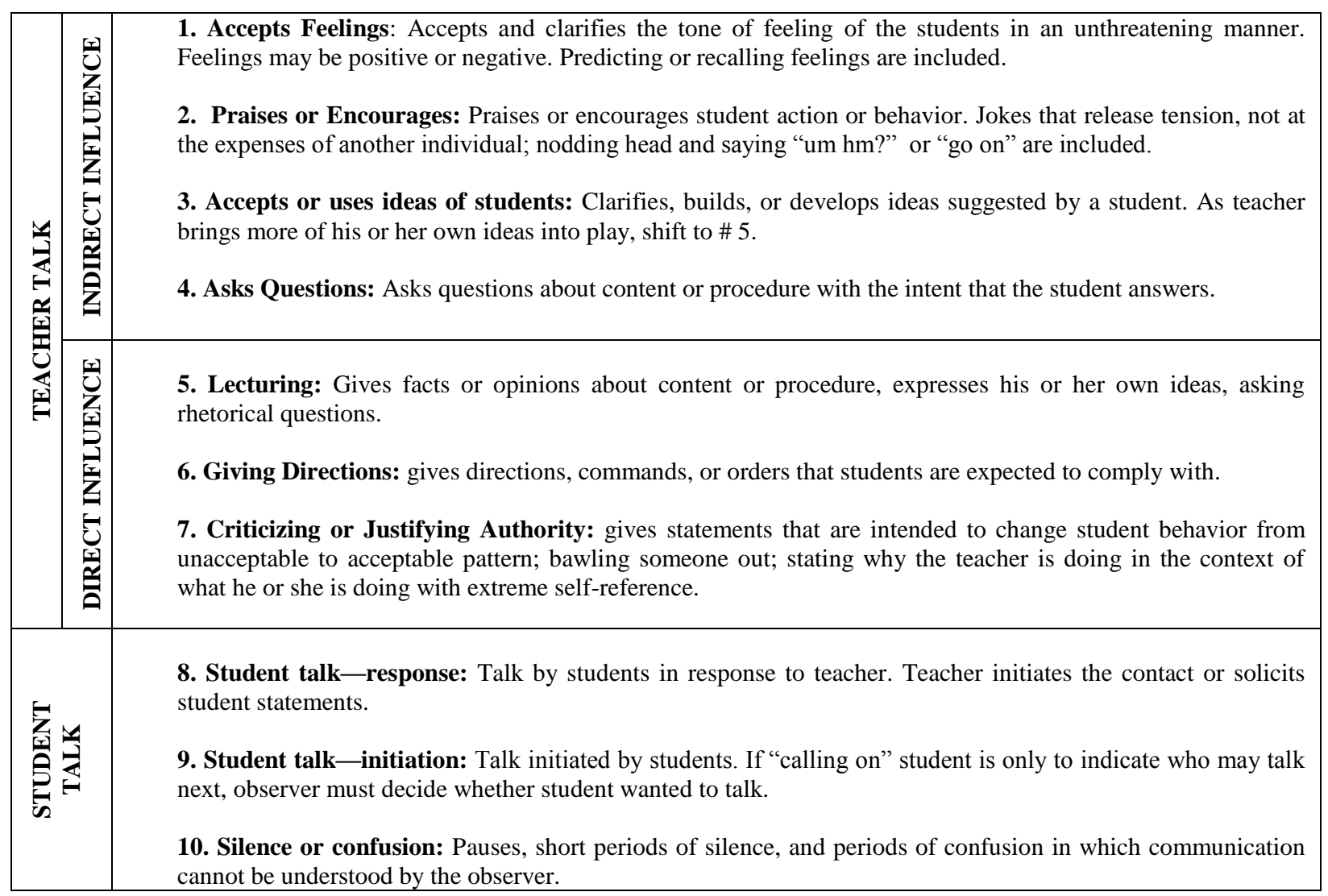

\section{Observational Sheet}

\begin{tabular}{|l|l|l|l|l|l|l|l|l|l|l|l|l|l|l|l|l|l|l|l|l|l|l|l|l|l|l|l|l|l|l|}
\hline 10 & 20 \\
\hline 1
\end{tabular}

Name of Teacher:

Class:

The above observational sheet represents 90 seconds for 10 categories of FIA. Each block in observational sheet represents 3 seconds.

\section{PROCEDURE}

The design of the study was observational, in order to secure data. The following observation procedure was adopted: 
1. In each 45-minute class, 13.50 minutes (810 seconds) were used for observation.

2. $\quad 13.50$ minutes ( 810 seconds) were divided in to nine observation sessions.

3. Each observation session was for the duration of 1.30 minutes ( 90 seconds).

4. One observation sheet was used for each observation session of 90 seconds.

5. Each observation session constituted 30 observation periods.

6. Each observation period was of 3 seconds duration.

7. The teacher's behaviour in each observation period of 3 seconds was observed, classified and recorded in the relevant block of the observation sheet until the termination of observation session of 90 seconds.

8. Stopwatch was used to note initiation and expiry of each observation period of 3 seconds.

9. Total time for observation in a single classroom comprised 13.50 minutes ( 810 seconds).

\section{DATA ANALYSIS}

After obtaining and encoding the data, it was tabulated, analyzed and interpreted by using a simple method.

1. The ratio between indirect influence and direct influence: The sum of column 1, 2, 3, 4, divided by the sum of columns 5, 6, 7 gives the ratio.

2. The ratio between positive reinforcement and negative reinforcement. The sum of column $1,2,3$ is to be divided be the sum of 6,7 .

3. Student participation ratio: The sum of column 8,9 is to be divided by total sum.

\section{RESULTS AND DISCUSSION}

The major purpose of the study was to explore the direct influence of the college teachers in the light of Flanders Interaction Analysis in our own context. The first row indicates Flanders Interaction Analysis and the first column indicates the number of observed ten classes in each table.

Table \# 1: Ratio of direct influence, reinforcement and Student participation In District Swat

\begin{tabular}{|c|c|c|c|c|c|c|c|c|c|c|}
\hline \multirow[t]{2}{*}{ No } & \multicolumn{4}{|c|}{ Indirect Influence } & \multicolumn{3}{|c|}{ Direct Influence } & \multicolumn{3}{|c|}{ Student participation } \\
\hline & 1 & 2 & 3 & 4 & 5 & 6 & 7 & 8 & 9 & 10 \\
\hline 10 & 129 & 102 & 441 & 501 & 4803 & 425 & 500 & 432 & 480 & 312 \\
\hline
\end{tabular}

1. The ratio between direct and indirect influence is 0.2047 , which indicates the direct influence of the teacher in the class.

2. The ratio between positive and negative reinforcement is 0.7264 , which shows that the teacher is not effective.

3. The ratio of student participation is 0.1264 , which indicates a low participation level of the students.

Table \# 2: Ratio of direct influence, reinforcement and Student participation In District Abbot Abad

\begin{tabular}{|c|c|c|c|c|c|c|c|c|c|c|}
\hline No & \multicolumn{1}{|c|}{ Indirect Influence } & \multicolumn{4}{c|}{ Direct Influence } & \multicolumn{6}{c|}{ Student participation } \\
\hline & $\mathbf{1}$ & $\mathbf{2}$ & $\mathbf{3}$ & $\mathbf{4}$ & $\mathbf{5}$ & $\mathbf{6}$ & $\mathbf{7}$ & $\mathbf{8}$ & $\mathbf{9}$ & $\mathbf{1 0}$ \\
\hline & & & & & & & & & & \\
10 & 84 & 57 & 255 & 516 & 5286 & 430 & 494 & 345 & 198 & 406 \\
\hline
\end{tabular}

1. The ratio between direct and indirect influence is 0.1468 , which indicates the direct influence of the teacher in the class.

2. The ratio between positive and negative reinforcement is 0.4285 , which shows that the teacher is not effective.

3. The ratio of student participation is 0.0721 , which indicates a low participation level of the students. 
Table \# 3: Ratio of direct influence, reinforcement and Student participation In District Kohat

\begin{tabular}{|c|c|c|c|c|c|c|c|c|c|c|}
\hline No & \multicolumn{1}{|c|}{ Indirect Influence } & \multicolumn{4}{c|}{ Direct Influence } & \multicolumn{6}{c|}{ Student participation } \\
\hline & $\mathbf{1}$ & $\mathbf{2}$ & $\mathbf{3}$ & $\mathbf{4}$ & $\mathbf{5}$ & $\mathbf{6}$ & $\mathbf{7}$ & $\mathbf{8}$ & $\mathbf{9}$ & $\mathbf{1 0}$ \\
\hline & & & & & & & & & & \\
10 & 199 & 129 & 709 & 1080 & 2849 & 518 & 438 & 831 & 561 & 795 \\
\hline
\end{tabular}

1. The ratio between direct and indirect influence is 0.5563 , which indicates the direct influence of the teacher in the class.

2. The ratio between positive and negative reinforcement is 1.0847 , which shows that the teacher is good.

3. The ratio of student participation is 0.2216 , which indicates a low participation level of the students.

Table \# 4: Ratio of direct influence, reinforcement and Student participation In District Peshawar

\begin{tabular}{|c|c|c|c|c|c|c|c|c|c|c|}
\hline No & \multicolumn{1}{|c|}{ Indirect Influence } & \multicolumn{4}{c|}{ Direct Influence } & \multicolumn{4}{c|}{ Student participation } \\
\hline & $\mathbf{1}$ & $\mathbf{2}$ & $\mathbf{3}$ & $\mathbf{4}$ & $\mathbf{5}$ & $\mathbf{6}$ & $\mathbf{7}$ & $\mathbf{8}$ & $\mathbf{9}$ & $\mathbf{1 0}$ \\
\hline & & & & & & & & & & \\
10 & 231 & 219 & 920 & 831 & 1653 & 339 & 330 & 1176 & 1221 & 1179 \\
\hline
\end{tabular}

1. The ratio between direct and indirect influence is 0.9478 , which indicates the direct influence of the teacher in the class.

2. The ratio between positive and negative reinforcement is 2.0478 , which shows that the teacher is good.

3. The ratio of student participation is 0.4203 , which indicates a low participation level of the students.

Table \# 5: Ratio of direct influence, reinforcement and Student participation In District D.I.Khan

\begin{tabular}{|c|c|c|c|c|c|c|c|c|c|c|}
\hline No & \multicolumn{1}{|c|}{ Indirect Influence } & \multicolumn{4}{c|}{ Direct Influence } & \multicolumn{4}{c|}{ Student participation } \\
\hline & $\mathbf{1}$ & $\mathbf{2}$ & $\mathbf{3}$ & $\mathbf{4}$ & $\mathbf{5}$ & $\mathbf{6}$ & $\mathbf{7}$ & $\mathbf{8}$ & $\mathbf{9}$ & $\mathbf{1 0}$ \\
\hline & & & & & & & & & 7 & 7 \\
10 & 171 & 201 & 585 & 762 & 3066 & 486 & 450 & 728 & 765 & 744 \\
\hline
\end{tabular}

1. The ratio between direct and indirect influence is 0.4295 , which indicates the direct influence of the teacher in the class.

2. The ratio between positive and negative reinforcement is 1.0224 , which shows that the teacher is good.

3. The ratio of student participation is 0.2309 , which indicates a low participation level of the students.

\section{Discussion}

Overall, fifty observations were carried out in five Districts of NWFP, as per the procedures mentioned in the research methodology. It was observed that in the majority of the observed classes in each district, the role of the English teachers was directive and they directly influenced the class. In a few classes, the indirect mode was utilized by the teacher. The English teachers verbally dominated the class. The majority of college level English teachers were observed to be more directive in their teaching.

The present study revealed that in the majority of the classes, the English students were passive and the environment of the classroom was autocratic. It was observed in the classroom that the majority of English teachers used a lecture method very frequently and asked just a few low-order questions. It was also observed that in the classes where interaction took place between teacher and students in terms of question and answers or discussion, the students enjoyed the class: after the class ended, there were no feelings of fatigue and boredom on their faces-they rushed out of class with pleasant noise and discussion among them, as already described by Bellack (1965). He has analyzed verbal exchanges between teacher and students and linked them to a pedagogical game: while in the classes where the teaching was directive and students were passive, he observed the students to be bored, and noted the students considered the class a prison. It was also observed during the study that when the teacher teaches through indirect modes in class (having a discussion, question-and-answer sessions, or seeking participation among the administration and students), it was considered it waste of time. 
Gage's (1978) present study revealed that the current teachings in the observed classrooms are lacking effective teaching.

The results of the study are consistent with the results of research conducted by Inamullah (2005), whom used the same instrument (F.I.A) for the purpose of exploring teacher-student interaction; and concluded that more than two thirds of classroom time was occupied by the teacher, i.e., the direct influence of the teacher in the classes.

The present study supports the research conducted by Begum (2006) on influence of teachers in different subjects at tertiary level in Kohat.

The results of the study are consistent with the results of research conducted by Inamullah (2006) about the influence of the teachers of various subjects only at University level in Kohat. In comparison with Gage's (1978) study, he wanted to examine the possible differences according to grade level. He found clear evidence that teachers who utilized the indirect mode produced greater academic gains. Bergum's (2006) observations were similar. To be fair, their results may be due to the process of observation of the class, where teachers were alert for observation.

Had the observations been made unobtrusively, the results would have been different. Another possible reason for the results might be that it was a just an observation with a small proportion of time.

The observations were not based on standard schedule. As such, its reliability and validity could not be tested. Still another possibility is that the observed classes were English subjects.

Still another reason might be the flaws and coding procedures used by the researcher regarding the influence of the teacher in the class. In the present study, the ratio between the direct and indirect influences the ratio between the positive and negative reinforcement, which were ultimately used for analysis and interpretation: the result might have been different if the steady state cell, content cross cell, constructive integration cell and vicious cells were used.

It would have been better if one more trained observer in coding process were involved in order to determine the inter-observation reliability, thus, making the observation more authentic and reliable.

\section{REFERENCES}

1. Begum,F.2006.Influence of the Teacher in the Class, IER, Kohat University

2. Bellack, A. 1965. The language of the Classroom. Teacher college press, New York.

3. Flanders, N. 1963. Intent, Action and Feedback: A preparation for teaching. Journal of Teacher of Education. New York. Pp 251-260.

4. $\quad$ Flanders, N. 1970 Analyzing Teacher Behavior. Addison-Wesley. Reading, Mass: P.171

5. Gage, N. L. 1978. The Scientific Basis for the Art of Teaching. Teachers College Press. New York: P-287

6. Gay,L R. 2000. Competencies for Analysis and Application ( $\left.5^{\text {th }} \mathrm{ed}\right)$. Educational Research. Florida International University. Pp.448-457.

7. Inamullah, M.2005. Patterns of classroom interaction, University of Arid Agriculture Rawalpindi, Pakistan p-129

8. Mary, B. R. 1986. Wait Time Slowing Down May be a Way Of Speed Up. Journal of Classroom Interaction. University of Boston. USA. Pp.43-50.

9. Norman, A. and C. Richard. 1994. Educational Psychology, a developmental approach. (6 $6^{\text {th }}$ Ed). McGraw Hill, New York. Pp 323-351.

10. UNDP. 1997. Human Development Report. Oxford university press, New York. P.89

11. Walberg, H. J. 1986. Synthesis of Research on Teaching. In M. C. Witt rock (Ed), Handbook of research on teaching. Paragon. New York. Pp. 214-229. 
NOTES 